\title{
Intergenerational Equity
}

\section{Ian McDonald}

$\mathrm{T}$ The projected ageing of the Australian population has led to fears that a huge increase in the burden of caring for older people will have unreasonable adverse effects on future living standards. These fears are often expressed in terms of ageing having bad implications for inter-generational equity. This paper discusses the principles involved in defining and interpreting intergenerational equity, with an orientation towards issues raised by the ageing population.

Inter-generational equity is restricted for the purposes of this paper to be an equitable distribution of economic wellbeing between generations. Economic wellbeing, often called utility by economists, is primarily determined by the level of consumption of goods and services per person. Other factors such as environmental protection, hours and effort of work and lower rates of unemployment will also affect economic wellbeing. However, in this paper the focus is on consumption with some comment on the disutility of work. Omitting the other influences does not affect the arguments put forward here, but should be borne in mind in interpreting the analysis. Both privately-financed consumption and government-financed consumption, such as consumption of governmentfinanced health services, are included.

The plan of the paper is as follows. It begins with a brief discussion of the complications for making inter-generational comparisons of wellbeing that arise from the structure of over-lapping generations and variable life-lengths that characterises the population. Evidence on the distribution of inter-generational wellbeing in Australia is then presented as a background to the subsequent theoretical discussion, which looks at the concept of intergenerational equity using the Ramsey model. The paper concludes with a discussion of some implications of inter-generational equity for long-term fiscal policy.

\section{Comparisons of Intergenerational Wellbeing}

In comparing the wellbeing of different generations, a considerable degree of complexity arises because at any point in time the population is comprised of a number of over-lapping generations. Furthermore, within any generation people will live for different lengths of time.

The wellbeing of an individual can be defined as lifetime wellbeing. Many economists would support this approach because it avoids, in some instances, misleading inferences. For example, the low income of an undergraduate medical student could be falsely interpreted as poverty if the high income in later years as a qualified medical practitioner is ignored.

Ian McDonald is Professor of Economics at The University of Melbourne. 
However, definition of the lifetime wellbeing of particular individuals can be problematical because of variations in individual life-lengths. Should an individual with a longer expected life and a low level of consumption per period be considered as well off as one with a shorter expected life and a high level of consumption per period?

For older people the general view is to regard wellbeing on a per period basis rather than a lifetime basis. Government support, such as the pension and health subsidies, continues for as long as people live. Government policy sets the pension in per period terms, currently at 26 per cent of average weekly earnings. Eligibility for health support is influenced more by an individual's health status than purely by age. So the longer-lived receive more lifetime consumption.

By considering consumption per period rather than life-time consumption one takes into account the variability of life length and accepts the position that the longer a person's life the greater should be their life-time consumption.

Government support until death can be classified as a 'mortality-contingent claim'. To some extent, the mortality-contingent nature of government benefits offers some insurance against 'longevity risk'. Survival implies the need for consumption in the surviving years, consumption that is extra to that needed by someone who dies at a younger age. However, Philipson and Becker (1998) criticise the mortality-contingent claim nature of government subsidies to the old because these claims may induce people to choose lives of excessive length and low quality per period.

In what follows, the focus is on wellbeing based on consumption per period. The lifetime dimension is captured partly by considering relative levels of wellbeing by age at a point in time, especially comparing the relative levels of consumption of older and young people, and partly by considering how consumption of people in given age groups changes over time.

\section{The Wellbeing of Older People}

In this section evidence about the wellbeing of older people in Australia at the current time and in the past, and projections of the wellbeing of older people in the future, are discussed. Then, on the basis of these patterns of wellbeing of older people, the question whether people in Australia are saving too little is addressed.

\section{Current wellbeing of older people}

Relative levels of total consumption, that is private plus government, by age for Australia suggest that older people enjoy substantial levels of consumption.

First consider the estimates for private consumption, which is consumption financed privately including from government pension payments, in Figure 1. People in the age groups 65 years and over consume 76 per cent of the level of consumption of those in the 25 to 64 year age group. The US has a similar relativity between young and old, see Kotlikoff, Spivak and Summers (1982). 
The estimates for private consumption in Figure 1 were obtained by manipulating data from the Household Expenditure Survey (HES) to allocate consumption between children and adults. In these manipulations, a child is assumed to consume half that of a younger adult.

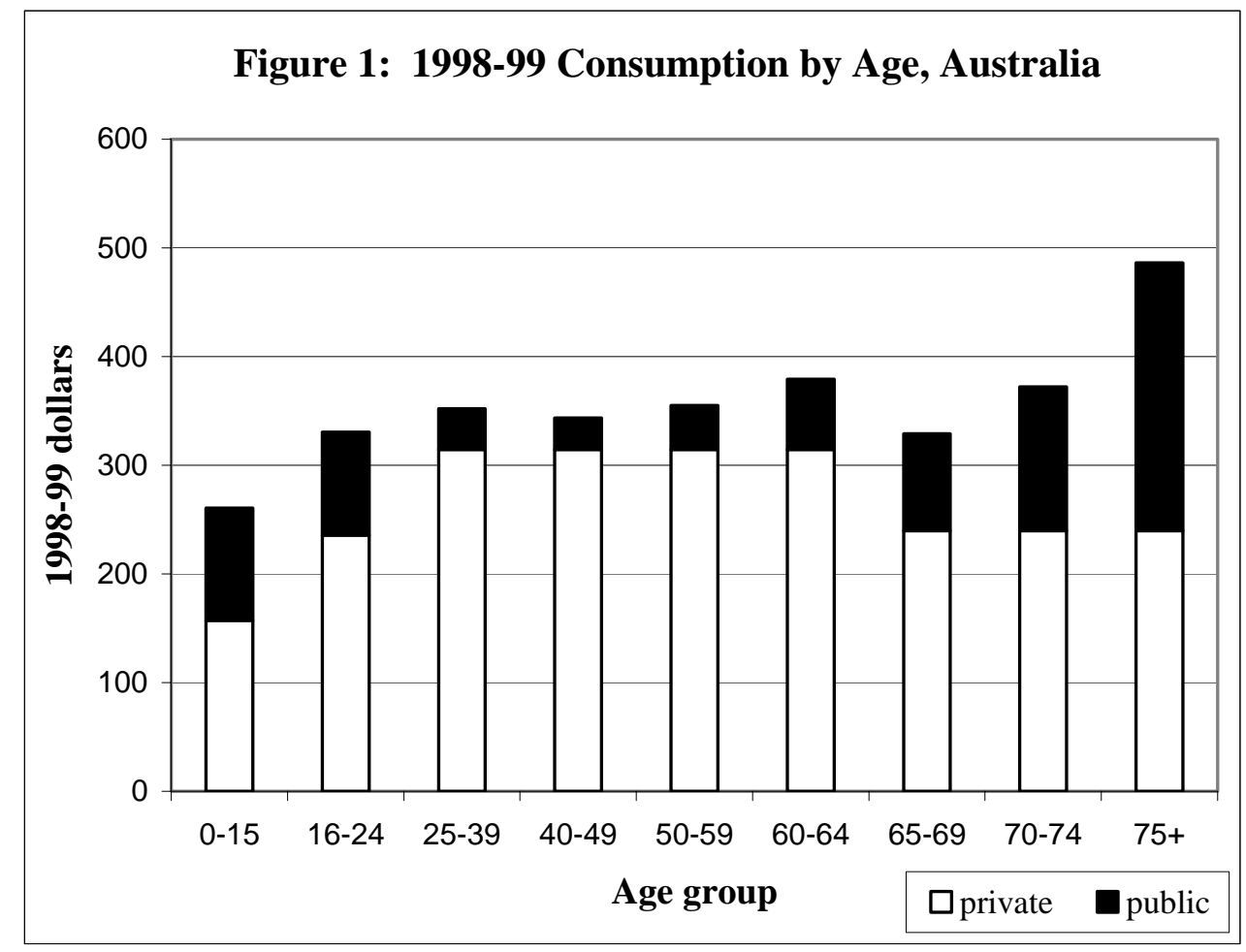

In view of the low incomes of older people, this relativity may appear surprisingly high. The government pension in Australia, the major income support for older people in general, is only 26 per cent of average weekly earnings. Given this, how can older people finance such a large consumption flow relative to younger adults of working age? The main reason is that, compared with younger adults, older people pay very small amounts of income tax and essentially no superannuation, mortgage payments and expenditures on children. From manipulating the 1998-99 HES, for adults aged 35-44 years, from their income of $\$ 560$, payments of $\$ 17$ for superannuation, \$25 for mortgage, \$121 for income tax, and $\$ 119$ for expenditures on children, a total of $\$ 281$, leave $\$ 279$. For those aged 65 years and over, whose incomes are $\$ 235$, these four items of payment account for only $\$ 20$ in total, leaving \$215. Thus an income ratio of old to young of 0.42 increases to a ratio of 0.77 after these four payment items are deducted.

Earlier HES surveys suggest that this pattern of the relative levels of private consumption by age has changed little in Australia over time. In the future, when superannuation income from the assets accumulated because of the superannuation 
guarantee levy kicks in, there will be some increase in the income of older people relative to younger adults and thus higher relative levels of private consumption by older people.

The data in the HES does not include the value of housing services consumed by owner-occupiers. However, given that both old and young consume such housing services, this exclusion does not affect significantly the point being made.

Second, government consumption expenditures, that is government-financed expenditures on education and health, by age are relatively high for children and older people but with older people getting considerably more than children, see Figure 1 (the data on government consumption expenditure by age in Figure 1 are described in more detail in Guest and McDonald, 2002). Education accounts for the high government expenditures on children, with health playing a secondary but important role, whilst for older people it is health expenditures that are important. Government health expenditures increase substantially with age for people 65 years and over, indeed for those aged 75 years and over, government health expenditures are almost double those of people aged 70 to 74 years.

In addition to the high government-financed health expenditures on older people, there are also substantial payments to older people through the old age pension. Thus the redistribution through government from young adults to older adults is substantial. The much greater income tax payments by young adults relative to older adults reflects this substantial redistribution.

What can be inferred from the empirical analysis above about the relative well being of young and old in Australia? Although total consumption per person by older people is greater than for younger adults, one cannot infer that older people have higher levels of well being. The greater consumption expenditures on older people reflect their lower health status. Older people need greater levels of consumption, especially health expenditures, to reach the same level of wellbeing.

However, allowances are needed for non-material determinants of wellbeing. Travers and Richardson (1993) have an extensive discussion and analysis of the influence of these factors. For older people, leisure is particularly important. Travis and Richardson (1993:39) show that allowing for leisure reduces the number of older people in the bottom quintile of the distribution substantially.

Happiness surveys support the idea that the old enjoy reasonable levels of wellbeing. These surveys are now well established throughout the world, see Frey and Stutzer (2002) for a recent survey. They ask people about their satisfaction with life. In general the finding is that the relation of happiness to age is Ushaped, with people in their 30 to 40 years the least happy of all age groups.

In conclusion, the considerable redistribution to the old in Australia at the current time makes an important contribution to their wellbeing and as a result leaves older people at comparable levels of wellbeing to younger people.

\section{Future living standards}

There appears to be widespread concern that the projected increase in the proportion of older people will jeopardise living standards in the future. It is not 
uncommon to see statements that living standards will actually fall in the future because of the increasing burden of older people to support.

To think about the future possibilities for living standards, it helps to assume that private consumption and public consumption remain fixed at their current relative amounts, at the relativities reported in Figure 1. Calculated on the basis of this assumption, the projected path of living standards from 1999 to 2050 is reported in Figure 2. The projection allows for expected demographic change according to a demographic projection described as 'Base'. Base is a continuation of current demographics, in particular a total fertility rate remaining at 1.75 , net immigration remaining at 0.5 per cent of population and a continuation of the current trend in the improvement in life expectancy. Under this evolution of the population, there will be considerable ageing, indeed the doubling of the proportion of aged people in the population over the next few decades. Even so, as Figure 2 shows, living standards are projected to rise at an annual rate of growth of 1.2 per cent from 1999 to 2050 implying that in 2050 living standards are projected to be 84 per cent above their 1999 level.

Because relative consumption levels are held constant in the projection reported in Figure 2, the increase shown applies to each age group. Thus, for example, the age group that is 65 to 69 years in 2050 will be 84 per cent better off in 2050 than is the 65 to 69 years age group in 1999 .

The large projected increase in living standards is driven mainly by the assumed annual rate of increase of labour productivity of 1.4 per cent, based on an assumed annual rate of increase of total factor productivity of one per cent. This rate of productivity growth is not an unreasonable expectation. It is equal to Australia's experience over the last 80 years. It is comparable to other highincome countries. There is no compelling reason to expect a growth slowdown.

It is also indicated in Figure 2 that the growth rate of living standards experienced from 1971 to 1999 was substantially higher than the projected future growth - 1.9 per cent relative to 1.2 per cent. This is so even although the growth rate of labour productivity was no higher. The difference partly reflects the difference in demographic experience. In the previous three decades the Australian population was 'younging' in that the ratio of working age population to total population increased. This gave a positive boost to the growth of GDP per person and, in the event, this positive boost was used by Australians to increase consumption. Thus the demographic dividend from the increasing ratio of working age to population was taken out in consumption rather than spread to the future by saving more. 


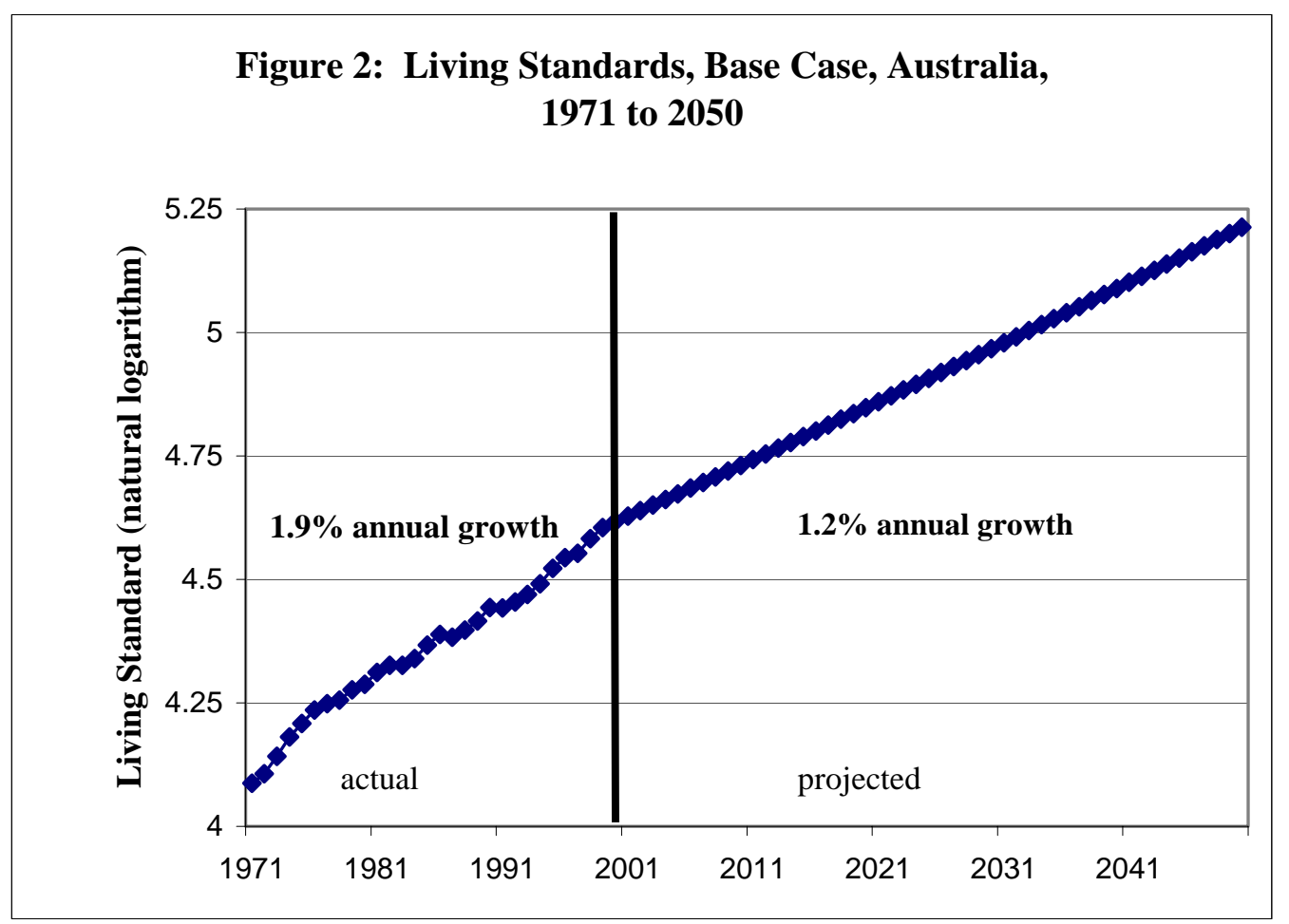

Source: Guest and McDonald (2001)

Note: The total consumption relativities by age are based on estimated rates in 1996-97, which differ slightly from the relativities, based on estimates for 1998-99, reported in Figure 1. To have used the 1998-99 consumption relativities would have made no effective difference to the projected living standards.

The projected ageing of the population has a negative effect on future living standards. With no ageing and the same productivity growth, living standards are projected to be 107 per cent higher by 2050 compared to 1999. But even after this 'loss' of 23 per cent, there remains a net increase of 84 per cent. Thus the effect on living standards of productivity growth dominates the effect of ageing.

Other projections in Guest and McDonald (2001) show that low fertility or higher immigration have little impact on the size of the future increase in living standards. This reflects the dominating role of increasing labour productivity.

In addition to work hours, the disutility of work is influenced by the effort or disagreeableness of work. This is not explicitly allowed for in the reported projections of future living standards. However, an improvement in work conditions at a similar rate to that enjoyed in the past can be assumed to accompany the projected increase in living standards. This is because the assumed rate of productivity growth is based on historical experience. That experience was accompanied by a substantial improvement in work conditions. It is reasonable to 
expect this to continue. Thus, if changes in the disutility of work are taken into account then the increase in future wellbeing will be even greater than suggested by the numbers reported above.

\section{Do people save too little?}

It is often argued that people do not save enough for their retirement (the opposite of the idea that there is a preference for a rising consumption profile). This argument has been used by some to advocate an extension of compulsory superannuation. Recently the idea of hyperbolic discounting has gained a lot of attention and has been used to suggest that people save too little. Hyperbolic discounting refers to a tendency observed in many people to use a higher discount rate for outcomes in the near future than for outcomes in the more distant future. Thus some people would like to save more tomorrow but are not prepared to increase saving today. This preference leads to permanent postponement of increased saving and so the increased saving never occurs.

A tendency to undersave has been inferred from the fact that consumption drops when people retire. For example, as reported above, evidence from the HES implies that people 65 years and over consume only 76 per cent of the consumption levels of younger adults. From this some draw the inference that after retirement consumption becomes 'income constrained' because people have not anticipated the drop in their retirement income. However, taking into account the cost of working, especially travel, clothing and food, and that the younger adults generally have higher lifetime incomes because of the secular increase in labour productivity, this suggestion of under-saving in general is not compelling. On the basis of US evidence, Kotlikoff, Spivak and Summers (1982) conclude:

despite the fact that a significant proportion of the elderly have little or no liquid or illiquid wealth, their Social Security, pension and earnings stream are sufficient to finance a level of old-age consumption that is as large or larger than they enjoyed in their youth.

As shown above, it is not just their pension and earnings stream but also their lower payments in tax, superannuation and child support that enable their consumption levels to be so high.

Of course, social security and government pensions contribute to the apparently healthy levels of consumption by older people. Were these not in place then perhaps older people would find that they had under-saved. The expected large increase in tax rates in the future implied by the combination of an ageing population and unchanged government policy on pensions and health, as in the Intergenerational Report (Australian Government, 2002), for example, raises the possibility that working taxpayers in the future will refuse to allow government policy to remain 'unchanged' and instead cut back on the growth of outlays per person. Should this be the response, then the living standards of older people will fall relative to younger people. But even so, the old in the future would still be substantially better off than the old are today. Calculations reported in Guest and 
McDonald (2003) suggest that, for the base case defined above, a change in government policy that leaves total government outlays at their current share of GDP implies that the living standards of the young and the old in 2050 will be 90 per cent and 65 per cent higher respectively than in 1999.

How much re-distribution towards older people will be chosen in the future by tax-payers remains to be seen. One may conjecture that rising living standards will make tax-payers more inclined to bear increased tax rates to support the old. The past pattern of transfers from the young to the old supports this conjecture. Relative to the incomes of the young, transfers to the old have grown over the last four decades. Government pensions increased from 23 per cent of average weekly earnings in 1960 to 26 per cent in 2002 (an increase of 13 per cent) and health expenditures more than doubled from 2.7 per cent of GDP in 1961-62 to about six per cent in 2002. Health expenditures are enjoyed disproportionately by older people. This pattern suggests further increases in the future, supporting the conjecture that the old will share in the general increase in productivity.

It is note-worthy that people appear to be rather malleable in their saving decisions. Thaler and Bernatzi (2004) report experiments where they increase employee's saving rates substantially simply by setting up a saving plan such that the default is to save. Usually joining a saving plan is a deliberate act. Thaler and Bernatzi reverse this by enrolling all employees in a company in a saving plan, 'Save More Tomorrow', with the option of opting out. They find this tends to increase saving rates from 3.5 per cent to 11.6 per cent in a little over two years. Thaler and Bernatzi (2004) interpret this as showing a tendency of people to under-save. But maybe people are not sure what to do and would, if they studied the HES, or this paper, be happy with their saving rates.

While in general it can be argued that people save adequately, there are significant individual differences. Some people save too little (and some no doubt too much). Kotlikoff, Spivak and Summers (1982) observe that the 'adequacy of wealth accumulation rises sharply with education' and with home-ownership.

\section{Achieving Intergenerational Equity}

From the discussion above, continuation of current rates of saving and redistribution in Australia imply that future levels of wellbeing of Australians will be considerably greater than current levels, even when allowance is made for the ageing population. How does this implication square with the concept of intergenerational equity? In this section the theory of optimal economic growth is used to address this question. This discussion suggests that the redistribution to older people in Australia today, although considerable, is below the level that would achieve inter-generational equity.

\section{Redistribution over time}

Economic analysis of the optimal or desirable outcome for intergenerational equity over time is based on the Ramsey model. In the Ramsey model, a social 
planner, the representative of the enfranchised citizen, determines consumption, saving and investment to maximise a social welfare function (SWF). The social welfare function embodies the valuations that the social planner places on consumption levels enjoyed by people.

In specifying the SWF, people can be disaggregated by various characteristics, which may be thought to be relevant to the decision to allocate consumption across people. One such characteristic of importance when planning for an ageing population is consumption efficiency. That is, the social planner may judge older people to be less efficient at creating wellbeing. The fact that older people consume relatively large amounts of health expenditures is suggestive of consumption inefficiency. How consumption efficiency is embodied in the SWF will affect the optimal distribution of consumption between young and old. We return to this consideration in the next sub-section.

The idea that the social planner is really the enfranchised citizen implies a link between what the social planner thinks is socially optimal and what individuals think is good for them. As economic thinking has shown at length from Adam Smith onwards, there are conditions where the latter implies the former. Perfect competition is one of these conditions. But these conditions when violated also imply that deviations between the socially optimal outcome and the decentralised outcome may occur. For example, people may be characterised by what Fehr and Schmitt (1999) call 'self-centred inequity aversion', that is they get enjoyment from giving to people less well-off provided other people with similar incomes to themselves also give. With regard to the support of the aged, workers may be self-centred inequity averse in that they would contribute to pension and health expenditures for older people provided all workers contribute. In a private market economy without government intervention to mandate contributions from all workers, redistribution to the aged may fall short of the level that workers, being self-centred inequity averse, would regard as desirable.

In the Ramsey model the SWF takes into account the time-dimension by using the rate of time preference to discount wellbeing in the future back to a present-value equivalent today. A positive rate of time preference implies that future wellbeing is 'worth less' in the social planner's decision-making relative to current wellbeing. For example, a rate of time preference of 3 per cent implies that a unit of wellbeing in 50 years time is worth only 0.228 units of current wellbeing. This low weighting of future consumption by the social planner will tend towards bringing consumption forward.

The time dimension in the Ramsey model is also used to introduce a rate of return on forgoing consumption into the social planner's decision making. Whilst the value of future consumption is discounted back to the present by the rate of time preference, abstaining from consumption at present yields over time a rate of return on saving. This return, the rate of interest, is determined by the marginal product of capital or, for a small open economy, the world rate of interest.

The social planner's allocation of consumption between enjoyment now and enjoyment in the future, and thus the decision on what will constitute intergenerational equity, will be influenced by the rate of time preference relative to 
the rate of interest. The optimal growth rate of consumption in the Ramsey model is equal to $(\rho-r) / \theta$ where $\rho=$ rate of time preference, $r=$ rate of interest and $\theta=$ degree of curvature of the social welfare function. A low rate of time preference, by implying a high weight on the enjoyment of consumption in the future, implies low consumption now, which leads to high consumption in the future. A low rate of interest implies the opposite - that is, it implies a low return on saving leading to a choice of high consumption now and thus low consumption in the future. From this we see that it is the difference between these two concepts that is the crucial variable in determining intergenerational equity.

A benchmark case is when that differential is zero, that is, when the rate of time preference is equal to the rate of interest. In this case the two variables cancel each other out implying that the socially optimal rate of growth of consumption per person is zero and so consumption levels and thus living standards are equalised over time.

On normative grounds, equalising living standards over time appears to be an equitable way to treat different generations. One may argue that the date at which one is born, being arbitrary, should not affect one's living standard. Treating generations equally can be reasonably described as the epitome of intergenerational equity.

Attractive as this perfect-equity outcome is, in an economy with a positive rate of growth of GDP per person it is for practical purposes impossible to achieve, or indeed to get close to. In principle, borrowing now from outside the economy can be used to finance increased consumption now. In the future, those borrowings can be repaid from the higher GDP per person, leaving consumption per person in the future no higher than now. However, with GDP per person increasing over a long period of time, the current level of borrowing from outside the economy would have to be huge to achieve perfect equity. The power of compound growth of GDP per person is so strong that massive debts would be required to raise consumption levels of people today to levels equal to consumption levels in the future, even allowing for the repayment of these debts in the future. At 1.5 per cent growth, GDP per person will more than double in 50 years, and so redistributions of significant proportions of this GDP would be required to equalise consumption per capita. Over 100 years, GDP per person would more than quadruple, implying redistributions of a staggering dimension.

Redistributions of these magnitudes are essentially impossible. Governments, and even more so individuals, do not have the credibility to borrow such amounts. In a closed economy, such as the world economy, there are no outside economies from whom to borrow, making the achievement of perfect equality over time essentially impossible.

A view about the ideal rate of time preference that is famous in economics is that of Ramsey, the creator of the Ramsey model, who argued that to 'discount later enjoyments...is ethically indefensible’, Ramsey (1928). Rawls (1972) takes a similar view. However, note that with a positive rate of interest, perfect equity between generations requires a positive rate of time preference, that is a lower valuation on the wellbeing of people in the future relative to the present. This 
lower valuation 'offsets' the interest gain from saving. Thus the combination of earning a return on saving of say 6 per cent is offset by depreciating future wellbeing by 6 per cent. So with a positive rate of interest for people to be treated equitably requires a lower valuation on wellbeing in the future.

In the case of perfect intergenerational equity, the share of aggregate consumption in GDP will be falling over time, from a level exceeding 100 per cent, made possible by borrowing, to, eventually, levels below 100 per cent, to create a surplus with which debt can be serviced. In contrast, the case given far more emphasis by economists is where the consumption share in GDP is constant. This is the steady state case. To achieve a steady state outcome, consumption per person has to grow at the same rate as GDP per person. This is a higher rate of growth of consumption per person than the zero growth in the case of perfect intergenerational equity. Thus the steady state outcome is not consistent with intergenerational equity. Instead, consumption is pushed to the future. To achieve this the rate of time preference has to be lower than in the perfect equality case, in particular less than the rate of interest.

To move in the direction of perfect inter-generational equity, rising GDP per person suggests a strong case for borrowing from the future. Practicalities prevent this occurring. However, it implies that economic policy should start from the presumption that future generations will be substantially better off than current generations.

\section{Theoretical bases for redistribution from young to old}

The discussion above showed that there is considerable redistribution in Australia from young to old. Furthermore, it was shown that, with positive growth of GDP per person, later generations will enjoy higher life-time wellbeing even if the current pattern of redistribution continues and the proportion of older people in the population increases in line with demographic projections. We will see that this has implications for the normative case for redistribution from young to old.

Equity between generations implies a strong case for redistribution from young to old. With growing GDP per capita the young will have higher lifetime wellbeing. Giving some of this to the old, whose lifetime incomes from work will be generally lower, will narrow somewhat the difference in lifetime wellbeing.

This redistribution can be viewed in two ways. First, that it is caused by the altruistic generosity of the young. The old are related to the young and are fellow citizens. It is natural for the young to have altruistic feelings toward the old and, being better off, to redistribute income to them. In general people are inequityaverse, even if self-centredness qualifies their readiness to give. Second, that it is a social contract between 'young' and 'old' in general. That is, the young may give to the old today on the understanding that tomorrow, when they are old, the young will give to them. This is not altruistic, because the giving is done in expectation of a return.

The social contract approach can be criticised for being a rationalisation rather than a contract. A social contract between young and old is not binding 
because it can be broken by the decisions of a younger generation. One feels that the widespread and longstanding nature of redistributions from young to old suggest a stronger basis in natural altruism rather than in contrived selfishness.

The social contract approach does lock in current policies of intergenerational redistribution. At the present time, for example, we are the beneficiaries of previous decisions to abstain from consumption. One might therefore argue that the social contract is in place and so the ideal degree of our generosity towards the future is already determined, with no say by us.

\section{Allowing for the consumption inefficiency of old people}

A factor that may, if the social planner decides redistribution by optimising a social welfare function based on individual wellbeing, temper the redistribution to the old is that, as noted above, older people are less efficient in consumption. That is, for a given level of consumption a representative older person enjoys lower wellbeing. As people get older, they require, on average, greater health expenditures to attain a certain level of fitness and ability. Becoming housebound reduces one's consumption possibilities and so one's consumption efficiency. This may reflect lower consumption possibilities for very old people. Consistent with this suggestion, Borsch-Supan and Stahl (1991) showed for the very old that consumption decreases with age by more than does income.

If, as in the Ramsey model, social welfare is based on maximising individual wellbeing subject to resource constraints then the optimum will in general require the least efficient consumers to enjoy lower utility. But how much lower depends on the social welfare function. A special case of the SWF is the Benthamite social welfare function, in which social welfare is the sum of individual wellbeing. Thus for Bentham, individuals are ranked equally, regardless of their levels of wellbeing. In this case, in the optimal outcome, less efficient consumers are allocated less consumption than more efficient ones. Thus older people would be allocated lower consumption levels, private plus public, than younger people.

The Benthamite outcome has been criticised by Sen (1973) for being too harsh on those who are less consumption efficient. Sen proposes that the social welfare function be specified to avoid these Benthamite outcomes such that a weak equity axiom is satisfied. According to that axiom, the less efficient are allocated at least as much consumption as other people. Note that the less consumption-efficient may still be worse off. It is a weak axiom. But not as badly off as under the Benthamite outcome.

In Australia it would appear that, broadly speaking, the weak equity axiom is satisfied. The total consumption levels of those aged 75 years or more are greater than younger adults. However, because of the weakness of this axiom, one could still reasonably advocate more redistribution to the old.

\section{Rawls' difference principle and intergenerational equity}

In his influential study, Rawls (1972) addressed explicitly the issue of intergenerational equity. Rawls rejected the Benthamite approach and instead, using 
the social contract approach of Locke, Rousseau and Kant, argued that the welfare of society should be evaluated by the welfare of the least well-off group. This is the famous difference principle. Rawls' approach can be thought of as a special case of the SWF approach discussed above.

In the inter-generational context, discussed by Rawls (1972:284-98), the difference principle implies the perfect equity outcome discussed above. However, Rawls does qualify this implication. He puts forward the 'just saving principle' according to which capital accumulation should be encouraged, and thus the consumption and wellbeing of the current generation constrained, in order to raise 'the standard of civilisation and culture' to a certain level. Rawls sees this requirement as a goal that can be attained such that 'once just institutions are firmly established, the net accumulation required falls to zero' (p. 287). Thus at that point the perfect equity outcome would be desirable. This 'last stage' is 'not one of great abundance', indeed 'it is a mistake to believe that a just and good society must wait upon a high material standard of life’ (p. 290).

Rawls points out the inexactness of the 'just saving principle' as a guide to the actual level of saving. There are no attempts that I am aware of to operationalise and quantify the 'just saving principle'. How close are we to the last stage? Perhaps we are already there? If so, the difference principle supports the desirability of perfect inter-generational equity.

In the practical outcome where the impossibility of perfect inter-generational equity is acknowledged and living standards grow over successive generations, redistribution to the aged is a move in the direction favoured by the Rawlsian difference principle even if it will fall short of full success.

\section{Inequitable Implications of Tax Smoothing in an Ageing Economy}

On efficiency grounds it is sometimes argued that fluctuations in government spending caused by say temporary events such as wars should not be accompanied by fluctuations in tax rates. Instead, tax rates should be set at constant levels such that the government budget is balanced on average over time. This argument is based on the increasing deadweight cost of taxation. As tax rates increase, their deadweight cost increases, as an approximation, by the square of the tax rate. Thus the increase in the deadweight cost caused by increasing a tax rate by one percentage point above the long run average is greater than the saving in deadweight cost from reducing the tax rate below the long term average by one percentage point. This implies that constant tax rates are better than fluctuating tax rates. Therefore it is best for governments to run budget surpluses when government spending is low and build up a stock of wealth to be used to partly finance budget deficits when government spending is high.

The classic example of tax-smoothing is the financing of wars. There are many examples of the large increase in government expenditures during a war being financed only partly by increased taxation. The difference is met from extra borrowing, which is subsequently paid off from budget surpluses generated by 
keeping tax rates high after the war. This pattern implies less deadweight cost than raising taxes during the war to the full amount to cover wartime expenditures.

In the context of the prospective ageing of the population, the efficiencyenhancing tax smoothing argument is interpreted by some to imply that tax rates should be increased ahead of the demographically-induced increase in government spending so that it can be financed partly out of the wealth built up during the period of budget surpluses. With this assistance in funding, tax rates will not have to be increased by such large amounts when government spending increases and so some deadweight costs will be avoided. This logic underlies the New Zealand Superannuation Fund.

However, the favourable efficiency implications of a pre-emptive increase in tax rates have to be balanced against the unfavourable equity implications. Clearly, by bringing tax increases forward to help finance later spending, consumption possibilities are being transferred from earlier to later generations. Given that the reasonable expectation, even when ageing is allowed for, is that later generations will be better-off than earlier generations, the pre-emptive increases in taxation will be a transfer from the less well-off to the more well-off.

With regard to the wartime financing example above, the burden of wartime expenditure is spread over future generations. This is the opposite pattern from that of pre-emptive increases in taxation to prepare for ageing and, in as far as future generations are better off, is equitable as well as efficient.

\section{Conclusion}

The discussion of inter-generational equity in this paper has made the following points. First, the empirical evidence suggests that there is substantial redistribution to the old in Australia and that this redistribution supports an apparently healthy living standard of the old in general compared with the young. Second, even although the population in Australia will age, this relativity will remain reasonably healthy, even if it suffers due to resistance to tax increases. Third, the idea of perfect equity between generations is attractive on ethical grounds. Perfect intergenerational equity implies very low saving. Fourth, whilst perfect equity between generations is attractive, it is in practice impossible to attain because there is no sensible way for those currently alive to enjoy now the fruits of future productivity growth.

That future generations will be better off than current generations has a number of implications. First, there is a strong case on equity grounds to redistribute wellbeing towards the old. The young who pay for the redistribution face expected incomes over their lifetimes that will exceed the lifetime incomes of their older contemporaries. This argument counters the claim that generations should 'pay for themselves over their lifetimes'. However, the redistribution to the old should be tempered by the consumption inefficiency of the old.

Second, in evaluating saving in the past, one should be wary of claims of excessive consumption. For example, in the 1970's and 1980's saving in Australia decreased. However, from today's vantage of higher living standards, it 
would be ungenerous to begrudge those less well-off people in the past the extra consumption they enjoyed because they saved less.

Third, whilst there appears to be, because of ageing, a slowdown in the rate of increase of living standards in Australia, the idea of forcing an increase in saving to avoid this slow-down does not seem to be equitable.

Fourth, policy makers should avoid calls to people to make sacrifices now for the unborn future generations. For example, it is not a reasonable argument to use population ageing as the prime reason to advocate reduced subsidies to health programs such as the Pharmaceutical Benefits Scheme on the basis of projections of future costs due to ageing. Neither is the suggestion that, in preparing for an ageing population with its implied increases in tax rates, a surplus should be built up in advance to mitigate future increases in tax rates (that is smoothing tax rates over time). But, there are efficiency gains from such smoothing. Following this logic, New Zealand, for example, has set up a New Zealand fund to assist with financing the burden in the future of the aged. However, because people in the future will be better off than people at present, the loss in equity caused by bringing tax increases forward counters the efficiency gains. Indeed intergenerational equity implies increasing tax rates over time as people get better off.

\section{References}

Australian Government (2002), 'Intergenerational Report 2002-03’, 2002-03 Budget Paper No 5, Commonwealth of Australia, Canberra.

Borsch-Supan, A., and K. Stahl (1991), 'Life-cycle Savings and Consumption Constraints', Journal of Population Economics 4:235-55.

Commonwealth Department of Community Services and Health (1990), The Impact of Population Ageing on Commonwealth and State Social Outlays 1987-88, Policy Development Division, Canberra.

Fehr, E., and K. Schmidt (1999), 'A Theory of Fairness, Competition and Cooperation', Quarterly Journal of Economics 114(3):817-68.

Frey, B., and A. Stutzer (2002), 'What Can Economists Learn from Happiness Research?', Journal of Economic Literature XL(2):402-435.

Guest, R. and I. McDonald (2001), 'Ageing, Optimal National Saving and Future Living Standards in Australia’, Economic Record 77(237):117-134.

Guest, R. and I. McDonald (2002), 'Would a Decrease in Fertility Be a Threat to Living Standards in Australia’, Australian Economic Review 35(1):29-44.

Guest, R. and I. McDonald (2003), 'How Much Support Will the Taxpayer Provide for Us When We Are Old?’, Economic Papers 22(1):1-12.

Kotlikoff, L., A. Spivak and L. Summers (1982), 'The Adequacy of Savings', American Economic Review 72(5):1056-69. 
Philipson, T., and G. Becker (1998), 'Old-age Longevity and Mortality Contingent Claims’, Journal of Political Economy 106(3):551-73.

Ramsey, A. (1928), ‘A Mathematical Theory of Savings', Economic Journal XXXVIII(152):543-59.

Rawls, J. (1972), A Theory of Justice, Clarendon Press, Oxford.

Sen, A. (1973), On Economic Inequality, Clarendon Press, Oxford.

Thaler, R., and S. Bernatzi (2004), 'Save More Tomorrow: Using Behavioural Economics to Increase Employee Saving’, Journal of Political Economy 112(1):S164-87.

Travers, P. and S. Richardson (1993), Living Decently: Material Well-being in Australia, Oxford University Press, Melbourne.

This paper is based on work commissioned by the Department of Treasury and Finance, State Government of Victoria. I thank Grant Clark and David Johnson and a referee for helpful comments on an earlier draft and Ross Guest for collaboration over a number of years. The views expressed in this paper are my responsibility and are not to be ascribed to the Government of Victoria. 